\title{
Use of $\mathrm{Ga}_{2} \mathrm{O}_{3}\left[\begin{array}{ll}1 & 0\end{array}\right]$ monocrystals as substrates for the synthesis of $\mathrm{GaFeO}_{3}$ thin films
}

\author{
S. Abad ${ }^{\text {a }}$, G.C. Vásquez ${ }^{\mathrm{b}}$, L. Vines $^{\mathrm{b}}$, R. Ranchal ${ }^{\mathrm{a}, \mathrm{c}, *}$ \\ a Dpt. Física de Materiales, Fac. CC. Físicas, Universidad Complutense de Madrid, Plaza de las Ciencias 1, Madrid 28040, Spain \\ ${ }^{\mathrm{b}}$ Centre for Materials Science and Nanotechnology, University of Oslo, N-0318 Oslo, Norway \\ ${ }^{\mathrm{c}}$ Instituto de Magnetismo Aplicado, UCM-ADIF-CSIC, Las Rozas, Spain
}

\section{A R T I C L E I N F O}

\section{Article history:}

Received 28 August 2019

Received in revised form 1 November 2019

Accepted 3 November 2019

Available online $\mathrm{xxxx}$

\section{Keywords:}

Magnetoelectricity

$\mathrm{GaFeO}_{3}$

Annealing

Structural properties

Magnetic properties

\begin{abstract}
A B S T R A C T
The aim of this work is to explore the use of thermal oxidation for the synthesis of $\mathrm{GaFeO}_{3}$ (GFO) thin films, by employing ex-situ annealed samples comprised of sputtered $\mathrm{Fe}_{72} \mathrm{Ga}_{28}$ layers deposited on top of $\mathrm{Ga}_{2} \mathrm{O}_{3}\left[\begin{array}{ll}1 & 0\end{array}\right]$ monocrystals. To avoid Ga evaporation, $\mathrm{Fe}_{72} \mathrm{Ga}_{28}$ were capped with $60 \mathrm{~nm}$-thick Mo. No surface damaged was observed when annealed between $200{ }^{\circ} \mathrm{C}$ and $400{ }^{\circ} \mathrm{C}$. Indications of GFO formation have been obtained by X-ray diffractometry in samples with a FeGa thickness of $560 \mathrm{~nm}$ annealed at $300{ }^{\circ} \mathrm{C}$ and $400{ }^{\circ} \mathrm{C}$. The hysteresis loops exhibit a coercive field close to the reported value for GFO when annealed at $400{ }^{\circ} \mathrm{C}$. All the experimental results encourage the application of this growth routine to synthetize high quality GFO thin films.
\end{abstract}

(c) 2019 Elsevier B.V. All rights reserved.
Magnetoelectricity can be exploited in multiferroic devices thanks to the manipulation of the magnetic properties by an electric field, and vice versa [1]. This is important since electric-field control of magnetism requires less energy than the use of magnetic fields [1]. GFO exhibit magnetoelectric properties [2-7] and high quality films can be deposited by pulsed laser deposition [8-13]. In a recent work, laser molecular beam epitaxy growth protocol was reported and based on the sequential deposition of $\mathrm{Ga}_{2} \mathrm{O}_{3}$ and Fe layers followed by a thermal treatment [14]. However, exsitu oxidation in oxygen atmosphere using uncapped sputtered FeGa layers was unsuccessful [15]. The main complications observed in our previous work were: i) annealing promoted the evaporation of $\mathrm{Ga}$ after the formation of $\mathrm{Ga}_{2} \mathrm{O}_{3}$ oxides whereas $\mathrm{Fe}$ mainly remained in its metallic state, and ii) large surface damages [15]. Therefore, capped FeGa layers to reduce damage, and using $\mathrm{Ga}_{2} \mathrm{O}_{3}$ as a substrate to enhance the Ga content in the oxidized layers might be a better strategy to obtain GFO films. Here, we propose to grow $\mathrm{FeGa}$ layers capped with $\mathrm{Mo}$ on top of $\mathrm{Ga}_{2} \mathrm{O}_{3}$ monocrystals that are subsequently ex-situ annealed to eventually synthetize GFO.

The samples studied in this work are: $\mathrm{Ga}_{2} \mathrm{O}_{3}\left[\begin{array}{lll}1 & 0 & 0\end{array}\right] / \mathrm{Fe}_{72} \mathrm{Ga}_{28}(x$ $\mathrm{nm}) / \mathrm{Mo}(60 \mathrm{~nm})$ in which the FeGa thickness $(x)$ has been modified

\footnotetext{
* Corresponding author at: Instituto de Magnetismo Aplicado, UCM-ADIF-CSIC, Las Rozas, Spain and Dpt. Física de Materiales, Fac. CC. Físicas, Universidad Complutense de Madrid, Plaza de las Ciencias 1, Madrid 28040, Spain.

E-mail address: rociran@ucm.es (R. Ranchal).
}

between $560 \mathrm{~nm}$ and $250 \mathrm{~nm}$ (samples scheme in Fig. 1). $\mathrm{Ga}_{2} \mathrm{O}_{3}\left[\begin{array}{lll}1 & 0 & 0\end{array}\right]$ monocrystals were obtained by mechanical exfoliation following the procedure presented in reference [16]. $\mathrm{Fe}_{72} \mathrm{Ga}_{28}$ and Mo were sputtered with a DC power of $90 \mathrm{~W}$ and an Ar pressure of $0.3 \mathrm{~Pa}$. Samples were ex-situ annealed at temperatures ranging from $200{ }^{\circ} \mathrm{C}$ to $700{ }^{\circ} \mathrm{C}$ in air atmosphere during $1 \mathrm{~h}$. Xray diffractometry (XRD) in the Bragg-Brentano configuration was performed in a Philips X'Pert MPD using the $\mathrm{Cu} \mathrm{K}_{\alpha}$ wavelength $(1.5406 \AA)$. Surface morphology was imaged by an Olympus BX60M microscope, and with a JEOL JSM-IT300 scanning electron microscope (SEM) working at $20 \mathrm{keV}$. The in-plane hysteresis loops were measured at room temperature in a vibrating sample magnetometer (VSM) from LakeShore.

After thermal treatments, the surface morphology was routinely checked to determine the optimum temperature range to minimize surface damage. For annealing temperatures between $500{ }^{\circ} \mathrm{C}$ and $700{ }^{\circ} \mathrm{C}$ we observed a surface full of craters, in contrast to the pristine surface observed for thermal treatments between $200{ }^{\circ} \mathrm{C}$ and $400^{\circ} \mathrm{C}$ (Fig. 1 ).

The XRD diffraction patterns taken from the samples are rather complex to analyze since the peaks related to the $\mathrm{Ga}_{2} \mathrm{O}_{3}$ monocrystals are very intense and can hide the substantially lower peaks of the other phases. However, small misalignments during XRD measurements enable to avoid the substrate peaks. The proximity between diffractions peaks makes also challenging to determine the evolution of the different phases with the annealing tempera- 


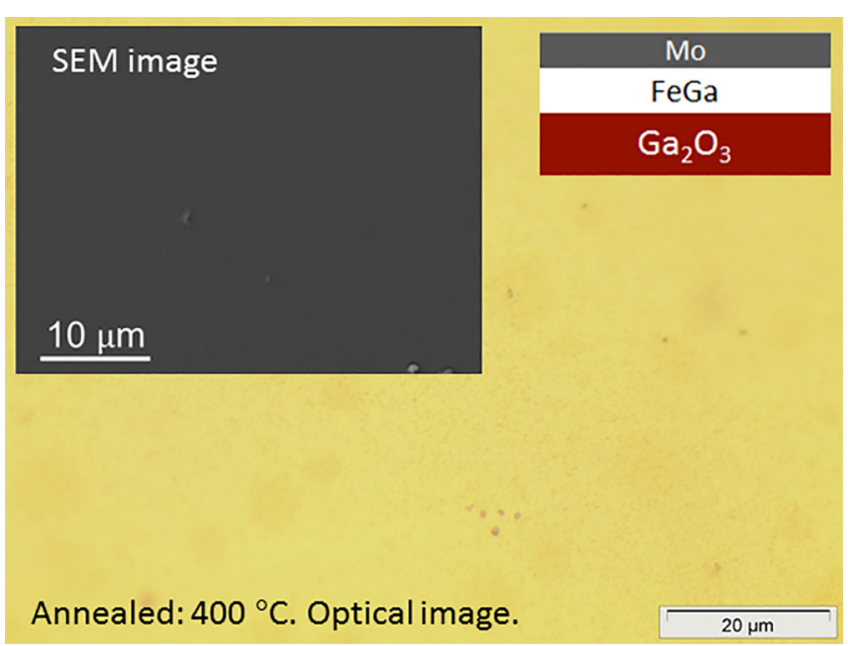

Fig. 1. Optical image of the sample $\mathrm{Ga}_{2} \mathrm{O}_{3}\left[\begin{array}{lll}1 & 0 & 0\end{array}\right] / \mathrm{Fe}_{72} \mathrm{Ga}_{28}(560 \mathrm{~nm}) / \mathrm{Mo}(60 \mathrm{~nm})$ annealed at $400{ }^{\circ} \mathrm{C}$. Right upper corner: scheme of the samples. Left upper corner: detail of the surface obtained by SEM microscopy.

ture and the FeGa thickness. In the graphs we have introduced the diffractogram of an as-grown FeGa layer as a reference to facilitate the discussion of the results (Fig. 2). For an annealing temperature of $200{ }^{\circ} \mathrm{C}$, the $\mathrm{FeGa}\left(\begin{array}{ll}1 & 10\end{array}\right)$ peak disappears in comparison to the asgrown layer but the temperature is too low to promote the formation of GFO as revealed by the absence of the GFO(2 40$)$ peak at $2 \theta \sim 43.77^{\circ}$ regardless of the FeGa thickness (Fig. 2a). This is also confirmed by the absence of any secondary peak related to GFO (2 3 1) close to the $\operatorname{Mo}\left(\begin{array}{lll}1 & 1 & 0\end{array}\right)$. For the sample with the lowest thickness, $250 \mathrm{~nm}$, a small diffraction peak related to FeMo is observed. Therefore, this thickness is not considered in the analysis for higher annealing temperatures. In Fig. 2b we present the comparison between samples annealed at $300{ }^{\circ} \mathrm{C}$. For this temperature, the $\operatorname{Mo}\left(\begin{array}{lll}1 & 1 & 0\end{array}\right)$ peak seems to be shifted towards higher angles that can be taken as an indication of the formation of GFO since the $\mathrm{GFO}(231)$ peak appears at $2 \theta=39.6^{\circ}$. This thermal treatment at $300{ }^{\circ} \mathrm{C}$ also seems to shift the $\mathrm{FeGa}(110)$ peak of the $560 \mathrm{~nm}$ thick FeGa layer to lower diffraction angles, i.e. towards the GFO (240) reflection, a further indication of the GFO formation
(Fig. 2b). However, the shift of the FeGa(llll 10$)$ peak is not so evident for the $400 \mathrm{~nm}$-thickness. At $400{ }^{\circ} \mathrm{C}$ and for a FeGa thickness of $560 \mathrm{~nm}$, the measured diffraction pattern is similar to that after annealing at $300{ }^{\circ} \mathrm{C}$, with the same indications for the formation of GFO. From these experimental results we can conclude that the formation of GFO is enhanced for an annealing between $300{ }^{\circ} \mathrm{C}$ and $400{ }^{\circ} \mathrm{C}$ for samples with a $560 \mathrm{~nm}$ FeGa thickness. However, the presence of metallic FeGa cannot be ruled out since no clear diffraction peaks but shifts with respect to those present in the as-grown reference FeGa have been observed in the XRD measurements.

The magnetic characterization reveals that the annealing at $300{ }^{\circ} \mathrm{C}$ for the $560 \mathrm{~nm}$-thick FeGa layer does not significantly modify the hysteresis loops (Fig. 3). The magnetic anisotropy present in the FeGa reference layer is almost unaffected by this annealing. However, for $400{ }^{\circ} \mathrm{C}$ it is obtained a larger modification of the magnetic anisotropy. In addition, it has been reported a coercive field $\left(H_{C}\right)$ between 70 and 90 Oe for GFO layers [14]. In the magnetic easy axis (EA) of the sample annealed at $300{ }^{\circ} \mathrm{C}$ we have obtained a $\mathrm{H}_{C}$ of 44 Oe that is close to that of the FeGa reference sample. The same can be said for the magnetic hard axis (HA) of this sample with a $H_{C}$ of 37 Oe. However, the sample annealed at $400{ }^{\circ} \mathrm{C}$ has a higher $H_{C}$ in these two axis, 75 in the EA and 72 Oe in the HA. This increase of $H_{C}$ can be taken as an indication of GFO formation. Therefore, the magnetic results indicate a higher proportion of GFO when annealed at $400{ }^{\circ} \mathrm{C}$ a $560 \mathrm{~nm}$-thick FeGa layer.

In conclusion, the experimental results of this work show the potential of using ex-situ annealings to produce GFO thin films when using capped FeGa layers sputtered on top of $\mathrm{Ga}_{2} \mathrm{O}_{3}\left[\begin{array}{lll}1 & 0 & 0\end{array}\right]$ monocrystals. However, to avoid surface damage it is necessary to restrict the annealing temperature to remain between $200^{\circ} \mathrm{C}$ and $400{ }^{\circ} \mathrm{C}$. XRD has provided indications of GFO formation for an FeGa thickness of $560 \mathrm{~nm}$ annealed between $300^{\circ} \mathrm{C}$ and $400{ }^{\circ} \mathrm{C}$. In addition, the sample annealed at $400{ }^{\circ} \mathrm{C}$ exhibits a $\mathrm{H}_{\mathrm{C}} \mathrm{clo}-$ ser to that reported in GFO.

\section{Declaration of Competing Interest}

The authors declare that they have no known competing financial interests or personal relationships that could have appeared to influence the work reported in this paper.
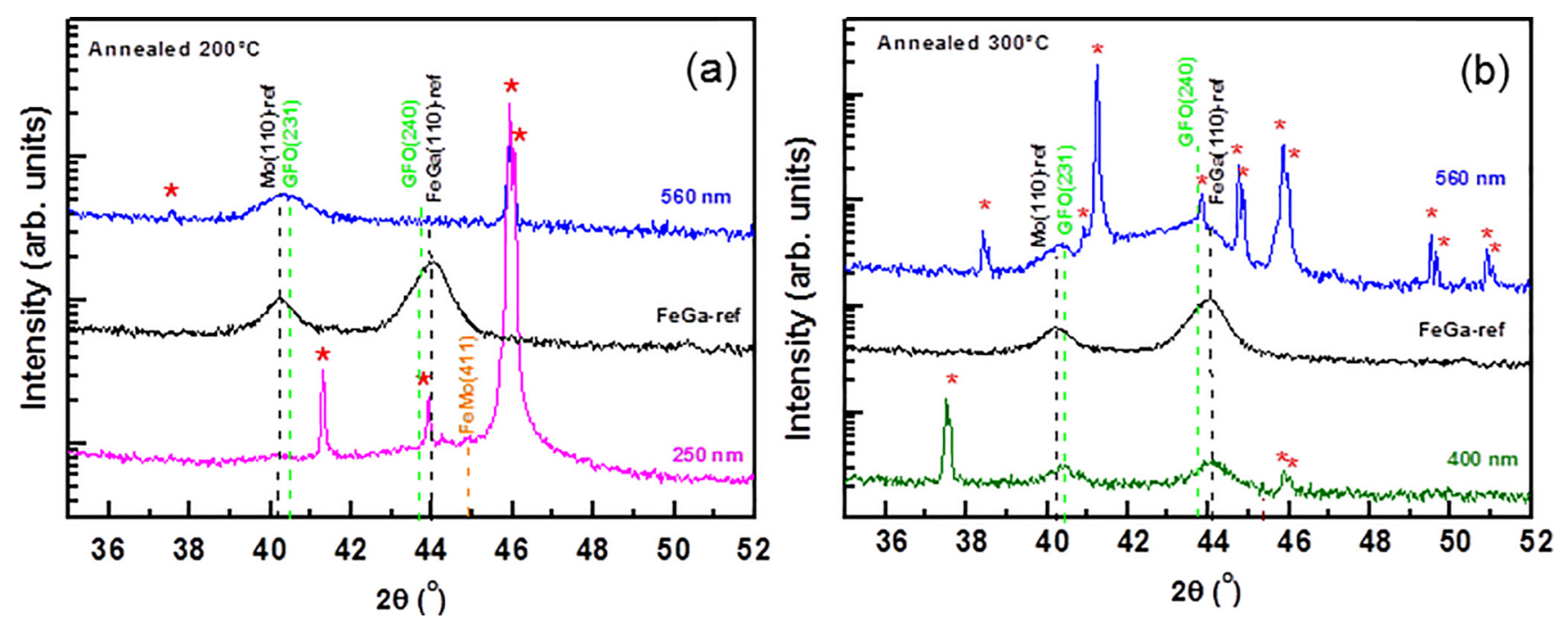

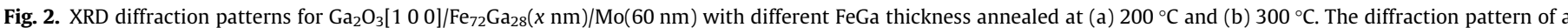

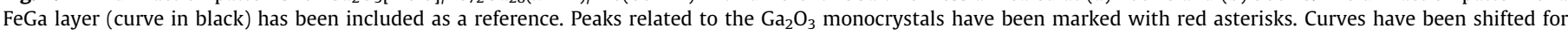
clarity. (For interpretation of the references to colour in this figure legend, the reader is referred to the web version of this article.) 


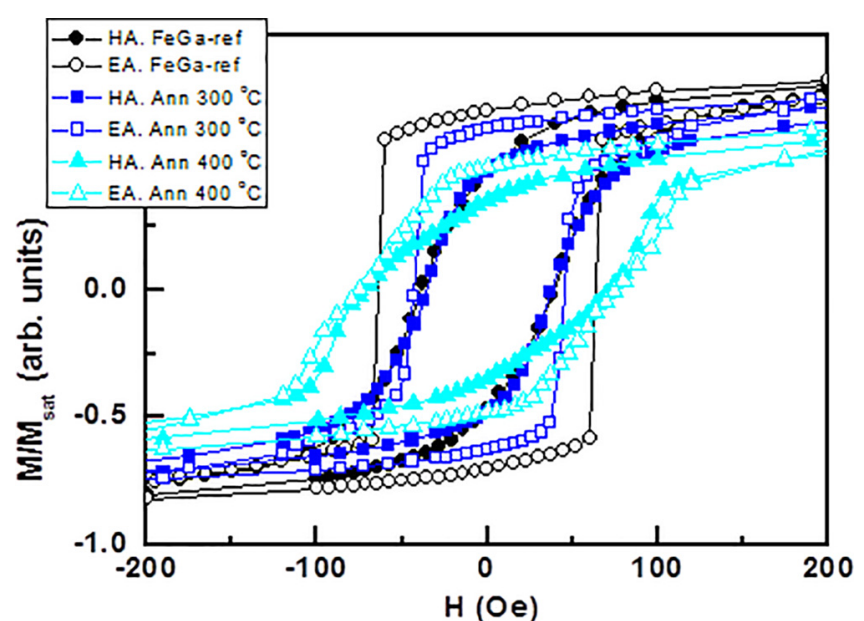

Fig. 3. Room temperature hysteresis loops for the as-grown FeGa reference layer $(\bullet, \bigcirc)$, and samples with $560 \mathrm{~nm}$-thick FeGa annealed at $300^{\circ} \mathrm{C}(\boldsymbol{\square}, \square)$ and $400^{\circ} \mathrm{C}$

$(\boldsymbol{\Delta}, \Delta)$. HA and EA refers to magnetic hard axis and magnetic easy axis, respectively.

\section{Acknowledgements}

We thank CAI Difracción de rayos-X of UCM for X-ray diffractometry measurements, and ICTS-ISOM (UPM) for using some of its facilities. This work has been financially supported through the projects MAT2015-66888-C3-3-R of the Ministerio de Economía y Competitividad of Spain (MINECO), and RTI2018-097895B-C43 of the Ministerio de Ciencia, Innovación y Universidades of Spain. The Research Council of Norway is also acknowledged for the financial support to the FUNDAMeNT project (No. 251131), and the Norwegian Micro- and Nano-Fabrication Facility, NorFab project (No. 245963/F50).

\section{References}

[1] N.A. Spaldin, R. Ramesh, Nat. Mater. 18 (2019) 203-212.

[2] G.T. Rado, Phys. Rev. Lett. 13 (1964) 335-337.

[3] J. Atanelov, P. Mohn, Phys. Rev. B 92 (2015), 104408.

[4] H. Niu, M.J. Pitcher, A.J. Corkett, S. Ling, P. Mandal, M. Zanella, K. Dawson, P. Stamenov, D. Batuk, A.M. Abakumov, C.L. Bull, R.I. Smith, C.A. Murray, S.J. Day, B. Slater, F. Cora, J.B. Claridge, M.J. Rosseinsky, J. Am. Chem. Soc. 139 (2017) $1520-1531$.

[5] K. Sharma, V.R. Reddy, A. Gupta, R.J. Choudhary, D.M. Phase, V. Ganesan, Appl. Phys. Lett. 102 (2013), 212401.

[6] N. Kida, Y. Kaneko, J.P. He, M. Matsubara, H. Sato, T. Arima, H. Akoh, Y. Tokura, Phys. Rev. Lett. 96 (2006), 167202.

[7] G. Zhong, Y. Bitla, J. Wang, X. Zhong, F. An, Y.-Y. Chin, Y. Zhang, W. Gao, Y. Zhang, A. Eshghinejad, E.N. Esfahani, Q. Zhu, C. Tan, X. Meng, H.-J. Lin, X. Pan, S. Xie, Y.-H. Chu, J. Li, Acta Materialia 145 (2018) 488-495.

[8] S.H. Oh, H. Lee, R.H. Shin, Y. Shin, C. Meny, W. Jo, Appl. Phys. Lett. 106 (2015), 142902.

[9] S. Mukherjee, A. Roy, S. Auluck, R. Prasad, R. Gupta, A. Garg, Phys. Rev. Lett. 111 (2013), 087601.

[10] S. Mukherjee, A. Garg, R. Gupta, Appl. Phys. Lett. 100 (2012), 112904.

[11] T. Katayama, S. Yasui, Y. Hamasaki, T. Shiraishi, A. Akama, T. Kiguchi, M. Itoh, Adv. Funct. Mater. 28 (2018) 1704789.

[12] T. Katayama, S. Yasui, Y. Hamasaki, M. Itoh, Appl. Phys. Lett. 110 (2017), 212905.

[13] M. Trassin, N. Viart, G. Versini, S. Barre, G. Pourroy, J. Lee, W. Jo, K. Dumesnil, C. Dufour, S. Robert, J. Mater. Chem. 19 (2009) 8876-8880.

[14] D. Guo, Y. An, W. Cui, Y. Zhi, X. Zhao, M. Lei, L. Li, P. Li, Z. Wu, W. Tang, Sci. Reports. 6 (2016) 25166.

[15] P. Álvarez-Álvarez, A. Prados, A. Muñoz-Noval, R. Ranchal, J. Alloys Compnd. 713 (2017) 229-235.

[16] J. Montes, C. Yang, H. Fu, T.-H. Yang, K. Fu, H. Chen, J. Zhou, X. Huang, Y. Zhao, Appl. Phys. Lett. 114 (2019), 162103. 